\title{
Impact of live stock development for sustainable livelihood generation through backyard poultry trainings
}

\author{
G. SRIDHAR AND B. SRIHARI RAO
}

\begin{abstract}
Bhagavatula Charitable Trust (BCT) is a non-proft organization working in the rural Visakhapatnam district since 1976. Hallmark of BCT's programs has been involvement community in their own development. Visakhapatnam Krishi Vigyan Kendra (KVK) is under the aeigs of BCT. KVK is offering necessary technical support during the follow up visits. There is good demand for the eggs from the improved breeds like Vanaraja, Giriraja and Gramapriya breeds. On an average the farmers are getting 170 eggs annually and $5 \mathrm{kgs}$ of meat from each bird giving an additional income Rs.2500. From a batch of 20-25 birds each family is getting an additional income of Rs. 1000 per month. The back yard poultry has given a boost to rural women and giving supplementary income and additional employment especially to house wives. Through study it was inferred that The Backyard poultry programme is found to quite feasible and handy program can be handled by wide range of rural women like agricultural labourers, Anganwadi teachers and housewives. It was found that on average there is 266.88 per cent of increased employment for rural women. Backyard Poultry Trainings proved that there is about 86 per cent gain in knowledge among the poultry farmers. The beneficiaries got hands on experience during the training program and started backyard poultry in their respective villages. Since, Backyard poultry can be operated throughout the year little infrastructure and investment, It is giving good employment opportunities to get themselves empowered.
\end{abstract}

KEY WORDS : Vanaraja, Backyard poultry, Employment, Knowledge

How To CITE THIS PAPER : Sridhar, G. and Rao, B. Srihari (2014). Impact of live stock development for sustainable livelihood generation through backyard poultry trainings. Res. J. Animal Hus. \& Dairy Sci., 5(2) : 92-101. 